\title{
In utero repair of fetal rat myelomeningocele affects neuromuscular development in the bladder
}

\author{
LIANGFENG TANG ${ }^{1}$, HAIJUN ZHONG ${ }^{1}$, HONG CHEN $^{1}$, JIAN SHEN $^{1}$, YUNLI BI $^{1}$ and XIANMIN XIAO ${ }^{2}$ \\ Departments of ${ }^{1}$ Urology and ${ }^{2}$ Surgery, Children's Hospital, Fudan University, Shanghai 201102, P.R. China
}

Received October 7, 2016; Accepted June 5, 2017

DOI: $10.3892 /$ etm.2017.4978

\begin{abstract}
Fetal repair of myelomeningocele (MMC) has been proven to be beneficial for the central nervous system development; however, the effect of fetal MMC repair on bladder function remains controversial. The objective of the present study was to establish an early timepoint for in utero MMC repair using a rat model, and to investigate the changes in bladder development subsequent to that intervention. Sprague Dawley rats were divided into the $\mathrm{MMC}$, MMC repair and control groups. MMC rat fetus models were created by treating pregnant rats with all-trans retinoic acid. The MMC defect was then repaired in utero at embryonic day 17 (E17) using a chitosan-gelatin membrane patch. Fetal rat bladders were removed at E19 and E21 in each group, as well as at stage E17 in the MMC and control groups. Differential expression of $\beta$-III-tubulin, $\alpha$-smooth muscle actin ( $\alpha$-SMA), nerve growth factor (NGF) and acetylcholinesterase (AChE) mRNA, and $\beta$-III-tubulin and $\alpha$-SMA protein in the bladder following fetal repair was measured and compared among the three groups. In addition, the expression of NGF mRNA was significantly elevated at E21 in the MMC group compared with that of the control group, however, the level decreased in the repair group at stage E21. The expression of $\alpha$-SMA mRNA significantly increased at E19 and then decreased at E21 in the repair group compared with that of the MMC group; however, there were no significant changes in $\alpha$-SMA protein following the repair. Furthermore, the repair enhanced $\beta$-III-tubulin mRNA expression at E19, but ameliorated the decrease of $\beta$-III-tubulin protein at E21. The expression of AChE mRNA increased in the MMC group at E19 and E21 compared with that of the control group, although it was not significantly altered following repair as compared with that of the MMC group. In conclusion, in the current study, abnormal neuromuscular development was observed in the MMC bladder, which
\end{abstract}

Correspondence to: Dr Yunli Bi, Department of Urology, Children's Hospital, Fudan University, 399 Wanyuan Road, Shanghai 201102, P.R. China

E-mail: biyunli@yahoo.com

Key words: myelomeningocele, fetal surgery, bladder development enabled a certain degree of improvement in the in utero MMC repair.

\section{Introduction}

Myelomeningocele (MMC) is a herniation of the neural elements through a posterior spinal and skin defect, and it results from failure of the neural tube to close during the early period of embryonic development (1). Live born infants with myelomeningocele have a mortality rate of $\sim 10 \%$ (2). Despite undergoing surgery after birth, long-term survivors have major disabilities, including paralysis and bladder dysfunction, because damage to the spinal cord and peripheral nerves that exists prenatally is usually irreversible after birth $(1,2)$. Neurogenic bladder with symptoms including incontinence and dysuria caused by central nervous system (CNS) injury is one of the most severe problems affecting patient renal function and quality of life (3). Myelomeningocele (MMC) is one of the most common causes of neurogenic bladder, accounting for the majority of congenital CNS malformations in children (4). CNS developmental defects, as well as mechanical and amniotic fluid chemistry injury to the spinal cord, simultaneously participate in the origin and progression of MMC during fetal development (5).

Significant advances have been achieved in the in utero MMC repair procedure, which has been demonstrated to be beneficial to CNS development, leading to improved lower limb function and a favorable prognosis (6-9). However, the improvement of bladder function following MMC repair remains limited and unclear, according to the results of several studies (10-12). Thus, it is clinically important to elucidate the mechanism of MMC-associated bladder development, which is likely to aid intrauterine repair and improve its results.

The aim of the present study was to establish an early timepoint for prenatal in utero intervention and MMC repair using a rat model, and to investigate the alterations in bladder development subsequent to the intervention. The expression levels of various bladder neuromuscular development markers, namely nerve growth factor (NGF), $\alpha$-smooth muscle actin ( $\alpha$-SMA), $\beta$-III-tubulin, and acetylcholinesterase (AChE), were determined at different timepoints in fetal development, including at embryonic day 17 (E17), E19 and E21, in MMC, MMC-repaired and control rats. 


\section{Materials and methods}

MMC animal model. A total of 133 female Sprague-Dawley rats (weight, 220-280 g; age, 12-18-weeks-old; Shanghai Laboratory Animal Center, Shanghai, China) that were pregnant for the first time were used in the current study. Animals were housed one per cage at $24^{\circ} \mathrm{C}$ with a natural dark/light cycle with food and water provided ad libitum.

Rats were divided into the MMC model, MMC repair and control groups. The control and MMC groups had 8 rats each, while 115 rats were prepared for the MMC repair group. The MMC fetal rat model was established by intragastric administration pregnant rats with all-trans retinoic acid (ATRA; Sigma Aldrich; Merck, Shanghai, China) dissolved in $2.0 \mathrm{ml}$ olive oil at a dose of $60 \mathrm{mg} / \mathrm{kg}$ body weight at stage E9.5 (13-15). Control rats were treated with $2.0 \mathrm{ml}$ olive oil by intragastric administration at E9.5. All experimental protocols were approved by the Institutional Review Board of the Children's Hospital of Fudan University (Shanghai, China).

In utero repair of $M M C$. For in utero repair in rat fetuses with MMC induced by ATRA, open fetal surgery was performed on 115 fetuses from 115 pregnant rats at E17 in order to repair the defect, and then evaluate the nerve and muscle development of the embryonic bladder tissue. A chitosan-gelatin film patch (Shanghai Key Laboratory of Tissue Engineering, Shanghai, China), an easily obtainable synthetic material, was used in the repair procedure.

Chitosan-gelatin film has been demonstrated to be one of the most widely used materials for tissue repair and drug delivery (16). The chitosan-gelatin patch was prepared in advance by drying a solution of $2.0 \%(\mathrm{w} / \mathrm{v})$ chitosan (Sinopharm Chemical Reagent Co., Ltd., Shanghai, China) and $4.0 \%(\mathrm{w} / \mathrm{v})$ gelatin mixed at a ratio of 3:7. For MMC repair, the pregnant rat was anesthetized with $250 \mathrm{mg} / \mathrm{kg}$ chloral hydrate (Sinopharm Chemical Reagent Co., Ltd.) by intraperitoneal injection, and the abdomen was opened to expose the MMC fetuses. The uterine wall was sutured with a 7-0 polypropylene polydioxanone-II (Ethicon, Shanghai, China) purse-string suture. Only one fetus in each pregnant female was selected for in utero MMC repair. In the purse-string suture area, a hysterotomy was performed to expose the back of one MMC fetus, and the chitosan-gelatin patch spotted with a Dermabond cyanoacrylate adhesive (Ethicon) was placed over the MMC area. The hysterotomy was then closed with the purse-string suture. The maternal rat used in the procedure was kept separately subsequent to recovering from the anesthesia. The steps involved in the surgical procedure are briefly shown in Fig. 1.

Tissue collection. Following surgery and at E19 and E21, the fetuses were removed by cesarean section. The pregnant rats were anesthetized using $250 \mathrm{mg} / \mathrm{kg}$ chloral hydrate by intraperitoneal injection, and then euthanized by cervical dislocation subsequent to fetal harvest. The linkage between the chitosan-gelatin patch and the skin tissue of the repaired fetuses was confirmed and any changes to the area after the repair were observed. Subsequently, the fetuses were divided into the MMC and the MMC repair group, while the control rat fetuses were harvested from the control group. At E19 and E21, 4 fetuses from the MMC repair group were prepared for frozen sectioning. The bladder tissues were carefully collected from the remaining fetuses from animals from each group under a dissecting microscope for use in the molecular detection of biomarkers.

Hematoxylin and eosin stain. Hematoxylin and eosin staining was performed to confirm the patch was attached to the skin tissue. The lower part of the fetal body was embedded in optimal cutting temperature compound (Sakura Finetek, Torrance, CA, USA) and chilled at $-24^{\circ} \mathrm{C}$ for $5 \mathrm{~min}$. The MMC repair location was cut into $5.0-\mu \mathrm{m}$ frozen sections, prepared into slides, and then stained with hematoxylin and eosin for observation.

Reverse transcription-quantitative polymerase chain reaction (RT-qPCR). The target gene mRNA expression levels in the bladder was measured by RT-qPCR. Initially, total RNA was extracted from bladder tissue samples using TRIzol reagent (Invitrogen; Thermo Fisher Scientific, Inc., Waltham, MA, USA) and then used in cDNA synthesis using a random primer according to the instructions provided with the Transcriptor First Strand cDNA kit (Roche Diagnostics, Shanghai, China). Next, qPCR was performed using a SYBR-Green qPCR kit (Takara Bio, Inc., Shiga, Japan) on an ABI 7000 device (Applied Biosystems; Thermo Fisher Scientific, Inc.) according to the manufacturer's instructions in order to evaluate the expression levels of target genes. Glyceraldehyde 3-phosphate dehydrogenase (GAPDH) was used as an internal reference. The sequences of the PCR primers were as follows: NGF forward, 5'-CGCTCTCCT TCACAGAGTTTTG-3', and reverse, 5'-GGCCAGGAT AGAAAGCTGCG-3'; $\alpha$-SMA forward, 5'-CATCACCAA CTGGGACGACA-3', and reverse, 5'-TCCGTTAGCAAG GTCGGATG-3'; $\beta$-III-tubulin forward, 5'-TGAGGCCTC CTCTCACAAGT-3', and reverse, 5'-TGTATAGTGCCC TTTGGCCC-3'; AChE forward, 5'-CCCTGTACCCTG GGTTTGAG-3', and reverse, 5'-CCAGATGAGGACAGG TGTGG-3'; GAPDH forward, 5'-CAGGGCTGCCTTCTC TTGTG-3', and reverse, 5'-AACTTGCCGTGGGTAGAG TC-3'. All qPCR reactions were performed in triplicate. The difference in threshold cycle $(\Delta \mathrm{Cq})$ value for gene-specific mRNA expression was calculated relative to the $\mathrm{Cq}$ value of GAPDH. Relative mRNA expression was calculated using the following formula: $2^{-\Delta \Delta \mathrm{Cq}}(17)$.

Western blot analysis. Total protein was extracted from the bladder tissue using radioimmunoprecipitation assay (Beyotime Institute of Biotechnology, Shanghai, China), and protein concentrations were tested using a BCA kit (Beyotime Institute of Biotechnology). Next, $35 \mu \mathrm{g}$ of each total protein sample was run on a $10 \%$ sodium dodecyl sulfate-polyacrylamide gel and transferred to a nitrocellulose membrane for immunoreaction analysis. After washing the membrane twice with TBST, the blotted membrane was blocked in freshly prepared TBS containing nonfat dry milk (3-5\%) for 30-60 min at room temperature with constant agitation. After washing again, antibodies against $\beta$-III-tubulin (dilution, 1:1,000; ab78078; Abcam, Cambridge, UK), $\alpha$-SMA (dilution, 1:200; ab5694; Abcam) and GAPDH (dilution, 1:2,000; HRP-60004; Mai Bio Co., Ltd., Shanghai, China), which 
A

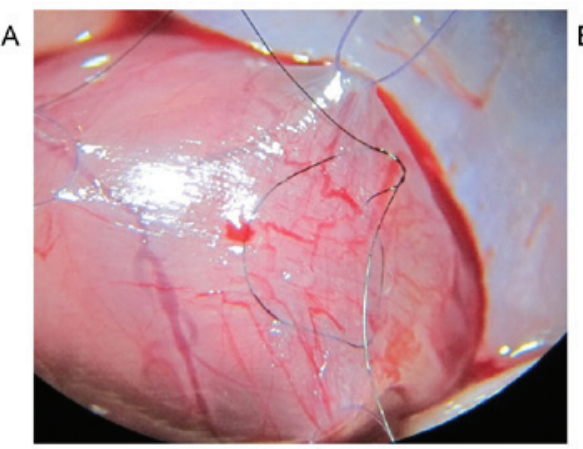

C

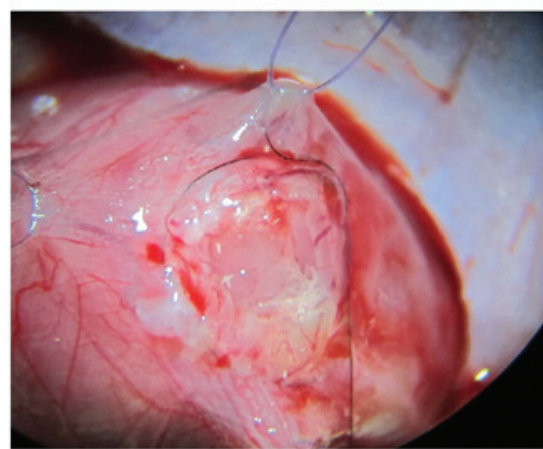

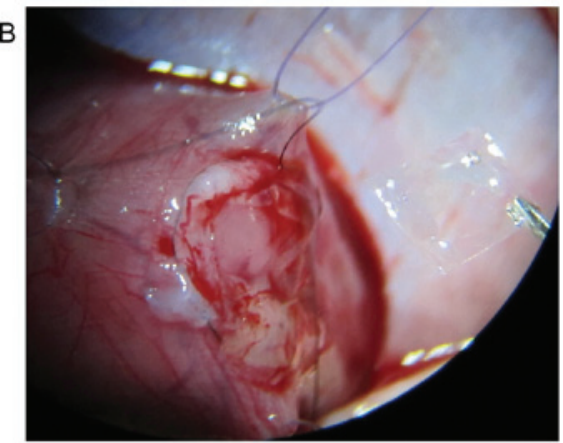

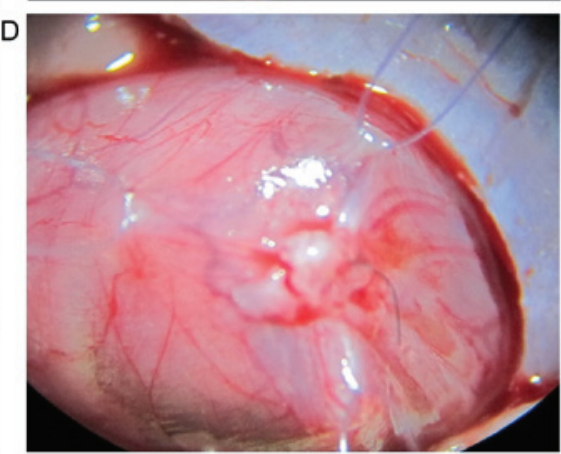

Figure 1. In utero MMC repair performed in rat fetuses in the present study. The brief steps of the procedure are shown: (A) Purse-string suture of uterine wall was established; (B) MMC defect was exposed; (C) the gelatin-chitosan membrane was inserted at the appropriate area of the MMC defect; and (D) the hysterotomy was closed using a purse-string suture. MMC, myelomeningocele.

served as the control, were used following the manufacturer's instructions. The primary antibodies were incubated overnight at $4^{\circ} \mathrm{C}$. Secondary antibodies (HRP-linked goat anti-mouse and rabbit polyclonal antibody; dilution, 1:2,000; HSA0002; Mai Bio Co., Ltd.) were added and incubated for $2 \mathrm{~h}$ at room temperature following membrane washing. Relative protein amounts compared with those of GAPDH were calculated based on the band gray values obtained with the ImageQuant LAS 4000 series device (GE Healthcare Life Sciences, Marlborough, MA, USA) following reaction with an enhanced chemiluminescence solution (Beyotime Institute of Biotechnology).

Statistical analyses. Data on the relative mRNA and protein amounts in each group are expressed as the means \pm standard deviation. Statistical analyses using least significant difference t-tests were conducted with SPSS version 13.0 (SPSS, Inc., Chicago, IL, USA). $\mathrm{P}<0.05$ was considered as an indicator of a statistically significant difference.

\section{Results}

Prenatal repair at E17. A total of 115 fetal surgeries were performed on 115 pregnant rats in the current study, and 33 (28.7\%) live births through caesarean section were achieved at stages E19 or E21. The main causes of repair failure were fetuses slipping out of the uterus during surgery or fetal death following intervention. The fetuses with successful MMC repair harvested at E19 and E21 were compared with the normal and MMC fetuses (Fig. 2). Frozen specimens with hematoxylin and eosin staining at stage E21 indicated that the chitosan-gelatin film covered the defect, and the patch had good attachment with the margin of fetal skin (Fig. 2).
High expression of NGF $m R N A$ in MMC bladder is altered following repair. NGF mRNA expression in the MMC group was significantly higher compared with that in the control group at E21 $(\mathrm{P}<0.001)$. NGF mRNA expression decreased in the repair group compared with that of the MMC group $(\mathrm{P}<0.001)$, although it remained significantly higher in comparison with that of the control group ( $\mathrm{P}<0.001$; Fig. 3 ). In addition, immunoblotting was performed to assess NGF protein expression in the fetal bladder; however, the protein level was undetectable using western blotting in all groups.

Fetal repair affects SMA expression in the fetal bladder. As shown in Fig. 4A, there was no significant difference in the expression of $\alpha$-SMA mRNA between the MMC and control groups at E17 and E19. However, the expression was significantly higher in the MMC repair group as compared with the control and MMC groups at E19 $(\mathrm{P}<0.001$ and $\mathrm{P}<0.01$, respectively). At E21, the expression of $\alpha$-SMA mRNA in the MMC group was significantly higher in comparison with that in the control group $(\mathrm{P}<0.001)$, but significantly decreased following repair $(\mathrm{P}<0.001)$, with no significant difference from the control group level (Fig. 4A). Furthermore, $\alpha$-SMA protein expression in the MMC group rats was significantly lower compared with the control group at E19 (P<0.05; Fig. 4B), but there was no significant difference in $\alpha$-SMA protein expression between the repair group and the MMC group at E19 and E21 (Fig. 4B).

Fetal repair inhibits the decrease of $\beta$-III-tubulin expression in the MMC bladder. At E19, $\beta$-III-tubulin mRNA levels significantly increased in the MMC group as compared with the control group $(\mathrm{P}<0.001$; Fig. $5 \mathrm{~A})$, although there was no significant difference in protein expression (Fig. 5B). However, 

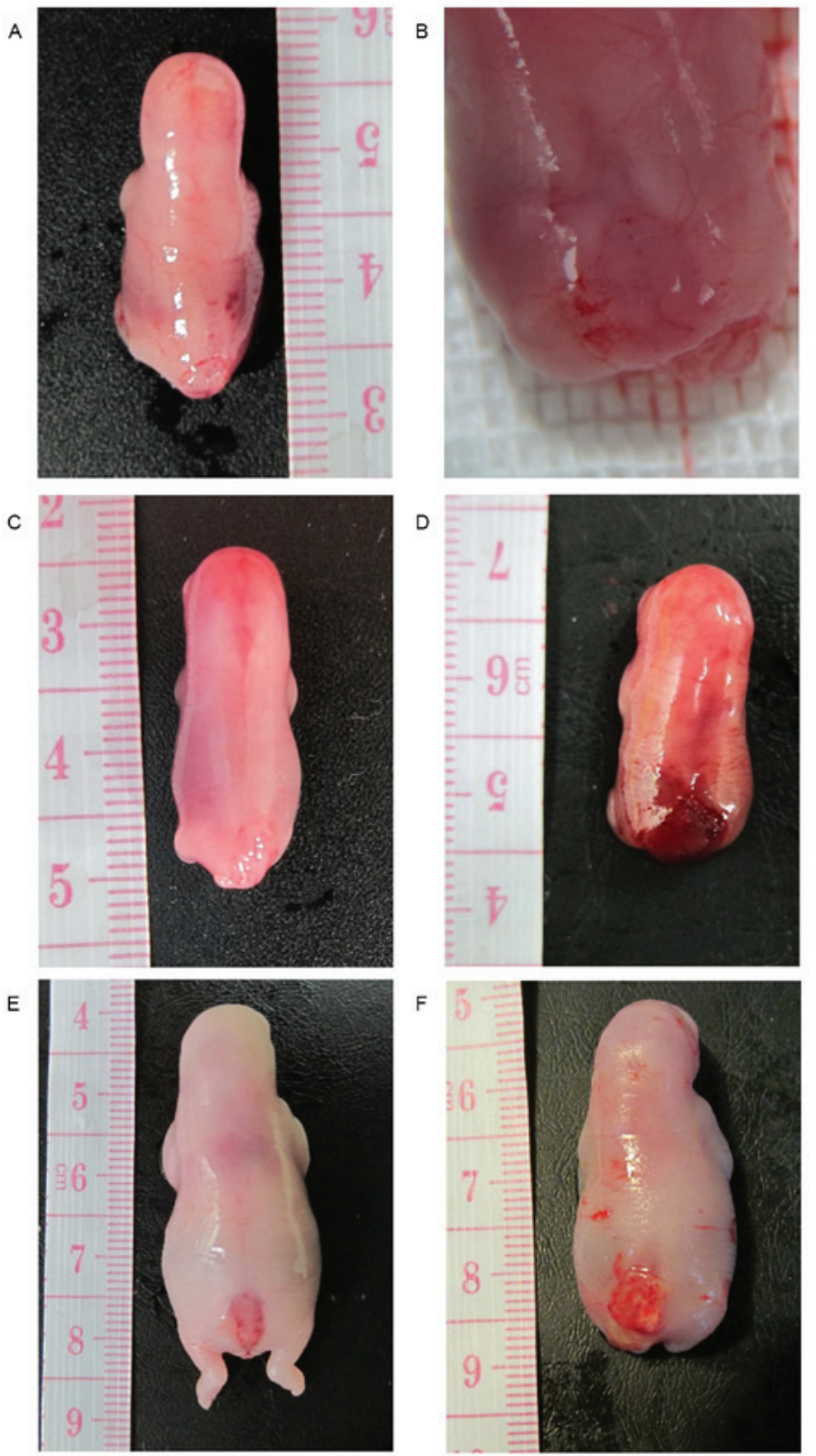

G
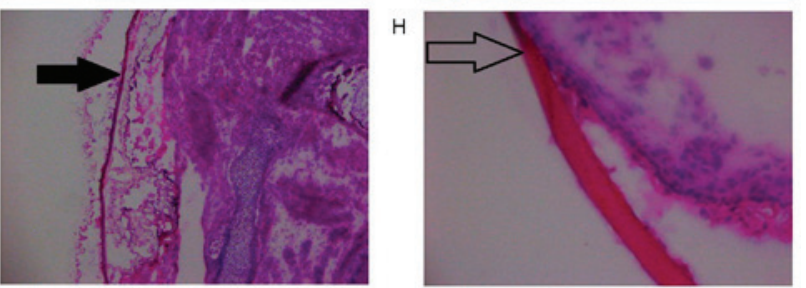

Figure 2. MMC fetuses at different gestational time points. MMC fetus is shown at (A) E17 and (B) at magnification of $\mathrm{x} 10$ at the same time point. (C) MMC fetus at E19. (D) E17 repaired MMC fetus at E19; (E) MMC fetus at E21. (F) E17 repaired MMC fetus at E21. (G) Hematoxylin and eosin staining of tissue from the operated area following repair at E21 (magnification, x50), showing the patch (black arrow) and the defect. (H) Good adhesion (open arrow) is observed between the chitosan-gelatin film and fetal skin at E21 (magnification, x400). MMC, myelomeningocele; E, embryonic day.

$\beta$-III-tubulin mRNA expression significantly increased $(\mathrm{P}<0.05)$, while the protein expression significantly decreased $(\mathrm{P}<0.001)$ in the MMC group compared with the control group at E21. Following the repair, the $\beta$-III-tubulin mRNA expression levels at E19 remained significantly higher in comparison with those of the control and MMC groups ( $\mathrm{P}<0.001$; Fig. 5A). At E21, no significant difference in $\beta$-III-tubulin mRNA

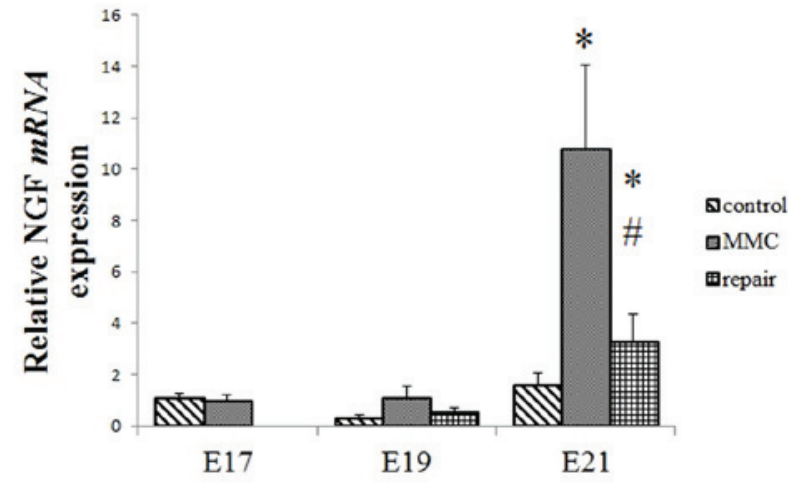

Figure 3. Expression levels of bladder NGF mRNA were analyzed using reverse transcription-quantitative polymerase chain reaction. All data are expressed as the mean \pm standard deviation ( $\mathrm{n}=4$ per group). ${ }^{*} \mathrm{P}<0.001$ vs. control group; ${ }^{\prime} \mathrm{P}<0.001$ vs. the MMC group. MMC, myelomeningocele; NGF, nerve growth factor; E, embryonic day.

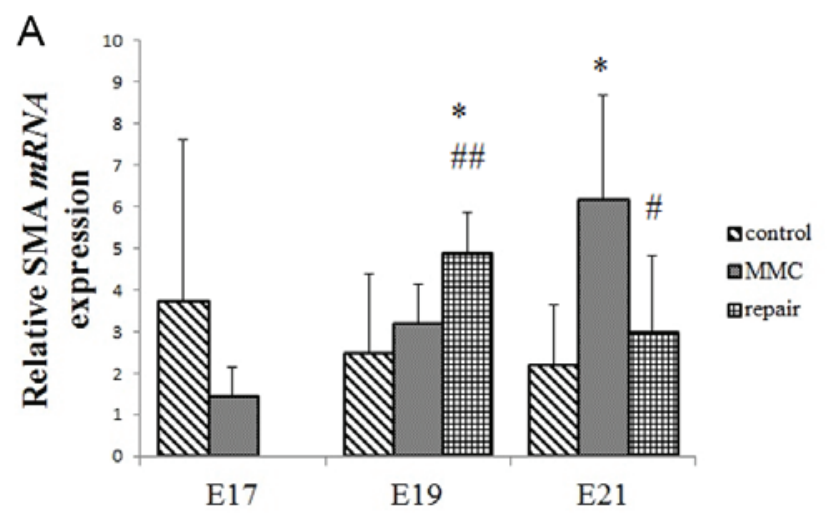

B

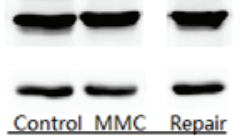

E19

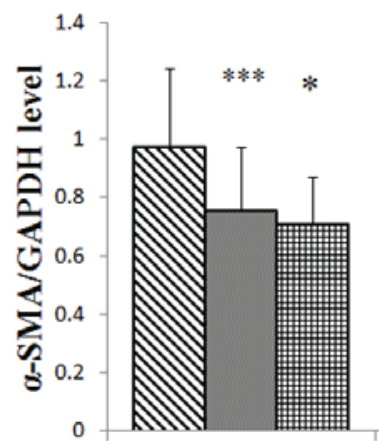

E19

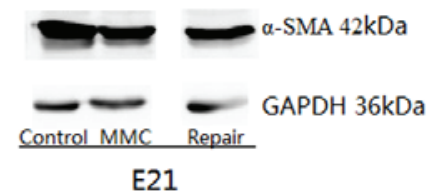

E21

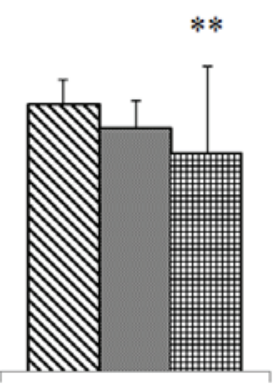

E21

ब control

$\square \mathrm{MMC}$

田 repair
Figure 4. Expression levels of bladder $\alpha$-SMA mRNA and protein. (A) $\alpha$-SMA mRNA levels were analyzed by reverse transcription-quantitative polymerase reaction. (B) $\alpha$-SMA protein levels were evaluated by western blot analysis. All data are expressed as the mean \pm standard deviation $(\mathrm{n}=4$ per group). ${ }^{*} \mathrm{P}<0.001,{ }^{* * *} \mathrm{P}<0.01$ and ${ }^{* * * *} \mathrm{P}<0.05$ vs. control group; ${ }^{*} \mathrm{P}<0.001,{ }^{\# *} \mathrm{P}<0.01$ vs. MMC group. MMC, myelomeningocele; $\alpha$-SMA, $\alpha$-smooth muscle actin; E, embryonic day.

expression was observed between the repair and MMC groups (Fig. 5A). The $\beta$-III-tubulin protein expression in the repair 

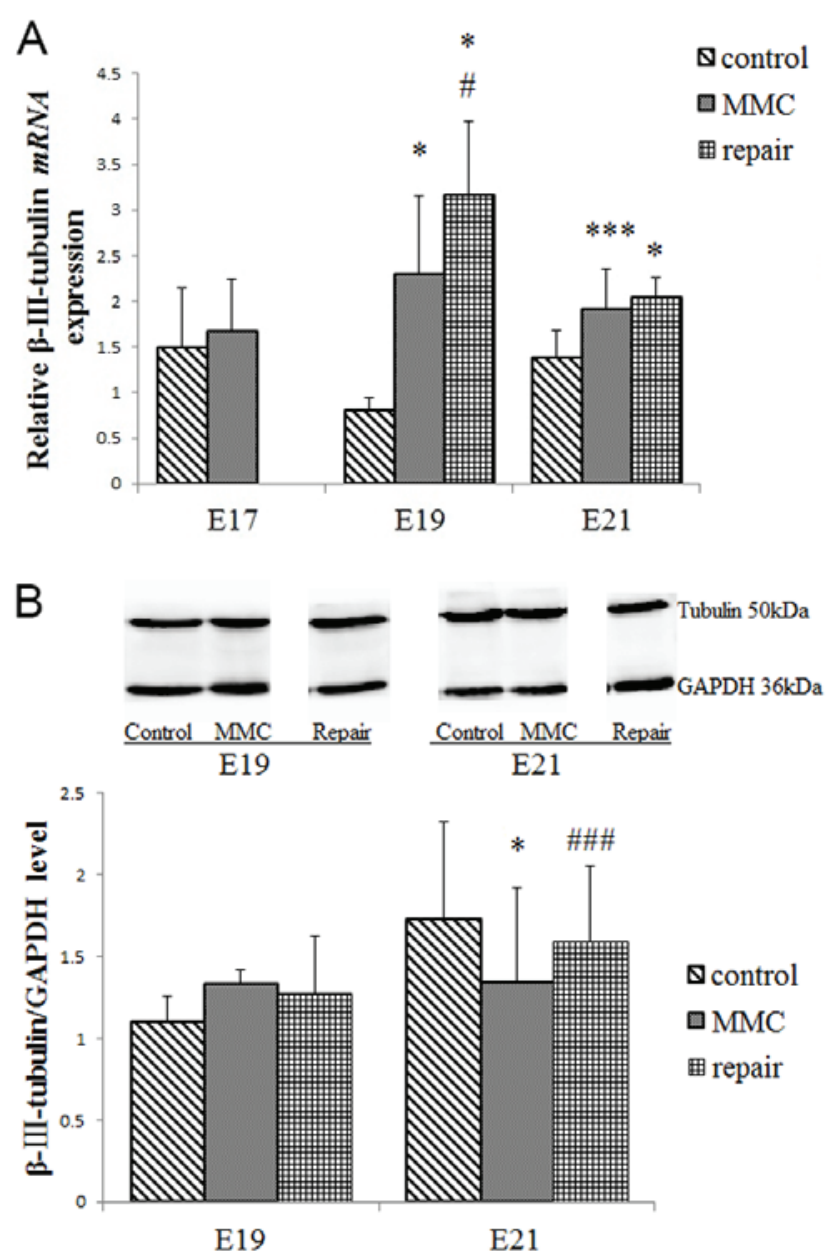

Figure 5. Expression levels of bladder $\beta$-III-tubulin mRNA and protein. (A) $\beta$-III-tubulin mRNA expression was evaluated using reverse transcription-quantitative polymerase chain reaction. (B) $\beta$-III-tubulin protein expression was evaluated by western blot analysis. All data are expressed as the mean \pm standard deviation ( $\mathrm{n}=4$ per group). ${ }^{*} \mathrm{P}<0.001,{ }^{* * *} \mathrm{P}<0.05$ vs.

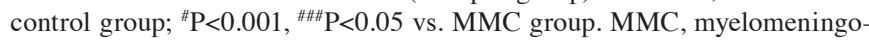
cele; E, embryonic day.

group was significantly increased compared with the MMC group at E21 ( $\mathrm{P}<0.05$; Fig. 5B), but no significant difference was observed compared with the control group (Fig. 5B).

Fetal repair does not affect the high expression of AChE $m R N A$ in the MMC bladder. AChE mRNA was highly expressed in the MMC group compared with that of the control group at E19 and E21 ( $\mathrm{P}<0.01$ and $\mathrm{P}<0.001$, respectively); by contrast, there was no significant difference in AChE mRNA expression between the repair and MMC groups at E19 and E21 (Fig. 6). However, the present study was unable to test the AChE protein for an exact comparison using western blot analysis in fetal bladder tissues due to the low expression of this protein.

\section{Discussion}

Spina bifida is one of the most common congenital anomalies of the central nervous system, and MMC is the most common form of spina bifida $(1,2)$. Since the implementation of folate supplementation and improved prenatal screening, the incidence of MMC has been decreasing in recent decades $(18,19)$.

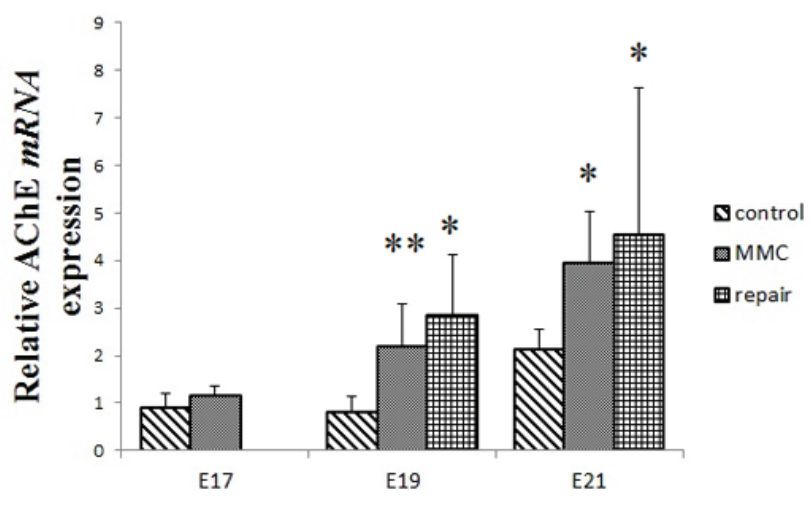

Figure 6. Expression levels of bladder AChE mRNA were analyzed using reverse transcription-quantitative polymerase chain reaction. All data are expressed as the mean \pm standard deviation ( $\mathrm{n}=4$ per group). ${ }^{*} \mathrm{P}<0.001$, ${ }^{* *} \mathrm{P}<0.01$ vs. the control group. MMC, myelomeningocele; AChE, acetylcholinesterase; E, embryonic day.

An incidence of 7.2-8.6 cases per 100,000 was reported in the newborn population with in-hospital births in the USA during the first decade of this century $(20,21)$. There is evidence of ongoing damage to the exposed neural tissue following the initial failure of neural tube closure, and it is considered to be a 'second hit' damage caused by trauma and/or chemical agents in the amniotic fluid $(5,22)$. It has been demonstrated that prenatal MMC repair improves clinical outcomes (23). The ATRA-induced fetal rat MMC model is widely used in the investigation of in utero $\mathrm{MCC}$ repair and this surgery can be performed as early in fetal development as E18, according to the literature (24). However, based on our experience, open fetal rat surgery can be performed as early as stage E17, although it should not be performed earlier due to the skin of fetal rats not being sufficiently solid for safe open surgical interventions prior to E17. Unlike the high successful rate in human MMC fetal surgery (5), the percentage of failure in rat E17 in utero intervention, which had not been reported in literature yet, is high. This is because the fetal rat at E17 is very small, and the operation is difficult to perform even after microsurgery training.

Nowadays, open fetal surgery of human MMC is performed after 20 weeks' gestation, at which point some spinal damage has already occurred (25). The current in utero intervention was performed only 1 day earlier than previous studies, which could have meaningful consequences. The earlier intervention prolonged the observation period after surgery and it simulated early fetal surgery. In the present study, at the stage of E17, the expression of the molecules of bladder neuromuscular development such as NGF, $\alpha$-SMA, $\beta$-III-tubulin and AChE were not observed to be different between the MMC and control groups; therefore, it was speculated that fetal MMC repair at E17 is an early stage, and that may affect neuromuscular development in the early developmental period. The early in utero MMC repair performed in the current study enabled a prolonged post-surgery observational period. The MMC fetus will not survive subsequent to delivery, as observed in the present study and reported by Danzer (26) due to feeding difficulty and maternal rat cannibalization; therefore, the prolonged observation period provides more opportunities to investigate alterations in the target organs following in utero repair. 
The Management of Myelomeningocele Study (MOMS) trial and post-MOMS practices demonstrated that prenatal repair of MMC was useful in improving motor outcomes and reducing the need for hydrocephalus shunting $(7,27)$. However, the effect of fetal MMC repair on bladder function remains controversial. Lee et al (12) reported that in utero closure of MMC in 11 children with a spinal defect did not significantly improve the lower urinary tract function when compared with 22 children who received repair surgery following birth. These results were not in agreement with the study by Carr (28), whose 5-year follow up study demonstrated that in utero MMC repair provided the patients with a higher percentage of continence in toilet training compared with those who received postnatal repair. However, prenatal surgery did not significantly reduce the requirement for clean intermittent bladder catheterization at 30 months of age (29). Therefore, the mechanism of bladder development following prenatal repair remains unclear.

In the present study, low expression levels of $\beta$-III-tubulin and $\alpha$-SMA protein were detected subsequent to prenatal MMC repair using a rat model, which suggested damage to the smooth muscle and nerves of the bladder in the MMC fetal rats. This observation was in accordance with the results of Danzer et al $(14,30)$ and Shen et al $(15)$. In addition, high expression of $\mathrm{AChE}$ in the MMC fetal rats indicated developmental abnormalities of the cholinergic nerve or neuromuscular junction; however, in utero repair did not induce a significant decrease in AChE mRNA expression. These results suggested that in utero MMC repair at E17 improved the peripheral nervous system development and reduced neurological damage in the fetal rat bladder to a certain extent, although development of the smooth muscle and cholinergic nerve remained poor.

Expression of urinary NGF originates from the bladder tissues, including the urothelium and smooth muscles (31), and is a biomarker of neurological injury and recovery, with significantly elevated levels observed in children with MMC $(32,33)$. Elevated expression of NGF mRNA in the bladder tissues results from the damage to the bladder urothelium and detrusor. In the present study, NGF mRNA expression in the bladder decreased following fetal MMC repair, which suggests that this early intervention ameliorated damage to the bladder.

In conclusion, open-surgery prenatal repair was conducted in the present study using a rat MMC model at the earliest possible gestational age, which is earlier than previous repair time points reported literature. The results revealed several molecular changes associated with bladder neuromuscular development. The prenatal repair resulted in inhibition of the elevated expression levels of bladder NGF mRNA and $\beta$-III-tubulin, which are biomarkers of neurological injury and peripheral nervous system development, respectively. By contrast, the expression levels of $\alpha$-SMA and AChE were not significantly altered by the prenatal repair. These results indicated abnormal neuromuscular development in the MMC bladder and certain degree of improvement subsequent to fetal repair. However, it is suggested that these results from animal studies are extrapolated cautiously to neurogenic bladder development in the human fetuses. Notably, in utero MMC intervention remains a challenging procedure in clinical practice, and further exploration using animal models and clinical trials is urgently required.

\section{Acknowledgements}

The current study was supported by grants from the National Key Clinical Specialty Construction Program of China (2014-2016) and the Youth Program of Shanghai Municipal Health Bureau (no. 20134Y108).

\section{References}

1. Copp AJ, Adzick NS, Chitty LS, Fletcher JM, Holmbeck GN and Shaw GM: Spina bifida. Nat Rev Dis Primers 1: 15007, 2015.

2. Mitchell LE, Adzick NS, Melchionne J, Pasquariello PS, Sutton LN and Whitehead AS: Spina bifida. Lancet 364: 1885-1895, 2004.

3. Larijani FJ, Moghtaderi M, Hajizadeh N and Assadi F: Preventing kidney injury in children with neurogenic bladder dysfunction. Int J Prev Med 4: 1359-1364, 2013.

4. Carr MC: Neuropathic bladder in the neonate. Clin Perinatol 41: 725-733, 2014.

5. Agarwal R, Thornton ME, Fonteh AN, Harrington MG, Chmait RH and Grubbs BH: Amniotic fluid levels of phospholipase $\mathrm{A}$ in fetal rats with retinoic acid induced myelomeningocele: The potential 'second hit' in neurologic damage. J Matern Fetal Neonatal Med 29: 3003-3008, 2016.

6. Adzick NS, Sutton LN, Crombleholme TM and Flake AW: Successful fetal surgery for spina bifida. Lancet 352: 1675-1676, 1998.

7. Adzick NS, Thom EA, Spong CY, Brock JW III, Burrows PK, Johnson MP, Howell LJ, Farrell JA, Dabrowiak ME, Sutton LN, et al: A randomized trial of prenatal versus postnatal repair of myelomeningocele. N Engl J Med 364: 993-1004, 2011.

8. Paek BW, Farmer DL, Wilkinson CC, Albanese CT, Peacock W, Harrison MR and Jennings RW: Hindbrain herniation develops in surgically created myelomeningocele but is absent after repair in fetal lambs. Am J Obstet Gynecol 183: 1119-1123, 2000.

9. Keller BA and Farmer DL: Fetal surgery for myelomeningocele: History, research, clinical trials, and future directions. Minerva Pediatr 67: 341-356, 2015.

10. Macedo A Jr, Leal M, Rondon A, Ortiz V, Moron AF and Cavalheiro S: Urological evaluation of patients that had undergone in utero myelomeningocele closure: A prospective assessment at first presentation and early follow-up. Do their bladder benefit from it? Neurourol Urodyn 34: 461-464, 2015

11. Chan YY, Sandlin SK and Kurzrock EA: Urological outcomes of myelomeningocele and lipomeningocele. Curr Urol Rep 18: 35, 2017.

12. Lee NG, Gomez P, Uberoi V, Kokorowski PJ, Khoshbin S, Bauer SB and Estrada CR: In utero closure of myelomeningocele does not improve lower urinary tract function. J Urol 188 (4 Suppl): 1567-1571, 2012.

13. Danzer E, Schwarz U, Wehrli S, Radu A, Adzick NS and Flake AW: Retinoic acid induced myelomeningocele in fetal rats: Characterization by histopathological analysis and magnetic resonance imaging. Exp Neurol 194: 467-475, 2005.

14. Danzer E, Kiddoo DA, Redden RA, Robinson L, Radu A, Zderic SA, Doolin EJ, Adzick NS and Flake AW: Structural and functional characterization of bladder smooth muscle in fetal rats with retinoic acid-induced myelomeningocele. Am J Physiol Renal Physiol 292: F197-F206, 2007.

15. Shen J, Zhou G, Chen H and Bi Y: Morphology of nervous lesion in the spinal cord and bladder of fetal rats with myelomeningocele at different gestational age. J Pediatr Surg 48: 2446-2452, 2013.

16. Wang K, Lin S, Nune KC and Misra RD: Chitosan-gelatin-based microgel for sustained drug delivery. J Biomater Sci Polym Ed 27: 441-453, 2016.

17. Livak KJ and Schmittgen TD: Analysis of relative gene expression data using real-time quantitative PCR and the 2 (-Delta Delta C (T)) method. Methods 25: 402-408, 2001.

18. Bowman RM, Boshnjaku V and McLone DG: The changing incidence of myelomeningocele and its impact on pediatric neurosurgery: A review from the Children's Memorial Hospital. Childs Nerv Syst 25: 801-806, 2009.

19. Gong R, Wang ZP, Wang M, Gao LJ and Zhao ZT: Effects of folic acid supplementation during different pregnancy periods and relationship with the other primary prevention measures to neural tube defects. J Matern Fetal Neonatal Med 29: 3894-3901, 2016. 
20. Harris DA, Cherian J, LoPresti M, Jea A and Lam S: Trends in epidemiology and hospitalization utilization for myelomeningocele repair from 2000 to 2009. Childs Nerv Syst 32: 1273-1279, 2016.

21. Boulet SL, Yang Q, Mai C, Kirby RS, Collins JS, Robbins JM, Meyer R, Canfield MA and Mulinare J; National Birth Defects Prevention Network: Trends in the postfortification prevalence of spina bifida and anencephaly in the United States. Birth Defects Res A Clin Mol Teratol 82: 527-532, 2008.

22. Drewek MJ, Bruner JP, Whetsell WO and Tulipan N: Quantitative analysis of the toxicity of human amniotic fluid to cultured rat spinal cord. Pediatr Neurosurg 27: 190-193, 1997.

23. Meuli M and Moehrlen U: Fetal surgery for myelomeningocele is effective: A critical look at the whys. Pediatr Surg Int 30: 689-697, 2014

24. Watanabe M, Kim AG and Flake AW: Tissue engineering strategies for fetal myelomeningocele repair in animal models. Fetal Diagn Ther 37: 197-205, 2015.

25. Danzer E, Johnson MP and Adzick NS: Fetal surgery for myelomeningocele: Progress and perspectives. Dev Med Child Neurol 54: 8-14, 2012

26. Danzer E, Zhang L, Radu A, Bebbington MW, Liechty KW, Adzick NS and Flake AW: Amniotic fluid levels of glial fibrillary acidic protein in fetal rats with retinoic acid induced myelomeningocele: A potential marker for spinal cord injury. Am J Obstet Gynecol 204: 178.e1-e11, 2011
27. Moldenhauer JS, Soni S, Rintoul NE, Spinner SS, Khalek N, Martinez-Poyer J, Flake AW, Hedrick HL, Peranteau WH, Rendon N, et al: Fetal myelomeningocele repair: The post-MOMS experience at the Children's Hospital of Philadelphia. Fetal Diagn Ther 37: 235-240, 2015.

28. Carr MC: Urological results after fetal myelomeningocele repair in pre-MOMS trial patients at the Children's Hospital of Philadelphia. Fetal Diagn Ther 37: 211-218, 2015.

29. Brock JW III, Carr MC, Adzick NS, Burrows PK, Thomas JC, Thom EA, Howell LJ, Farrell JA, Dabrowiak ME, Farmer DL, et al: Bladder function after fetal surgery for myelomeningocele. Pediatrics 136: e906-e913, 2015.

30. Danzer E, Radu A, Robinson LE, Volpe MV, Adzick NS and Flake AW: Morphologic analysis of the neuromuscular development of the anorectal unit in fetal rats with retinoic acid induced myelomeningocele. Neurosci Lett 430: 157-162, 2008.

31. Seth JH, Sahai A, Khan MS, van der Aa F, de Ridder D, Panicker JN, Dasgupta P and Fowler CJ: Nerve growth factor (NGF): A potential urinary biomarker for overactive bladder syndrome (OAB)? BJU Int 111: 372-380, 2013.

32. Korzeniecka-Kozerska A, Porowski T, Michaluk-Skutnik J, Wasilewska A and Plonski G: Urinary nerve growth factor level in children with neurogenic bladder due to myelomeningocele. Scand J Urol 47: 411-417, 2013.

33. Sekerci CA, Isbilen B, Ișman F, Akbal C, Simşek F and Tarcan T: Urinary NGF, TGF- $\beta 1$, TIMP-2 and bladder wall thickness predict neurourological findings in children with myelodysplasia. J Urol 191: 199-205, 2014 